\title{
GEOLOGICAL FEATURES MAPPING USING PALSAR-2 DATA IN KELANTAN RIVER BASIN, PENINSULAR MALAYSIA
}

\author{
Amin Beiranvand Pour*, Mazlan Hashim \\ Geoscience and Digital Earth Centre (Geo-DEC) \\ Research Institute for Sustainability and Environment (RISE) \\ Universiti Teknologi Malaysia (UTM), 81310 UTM Skudai, Johor Bahru, Malaysia \\ *Corresponding author: a.beiranvand@utm.my
}

KEY WORDS: PALSAR-2; Geological features mapping; Kelantan River basin; Peninsular Malaysia

\begin{abstract}
:
In this study, the recently launched Phased Array type L-band Synthetic Aperture Radar-2 (PALSAR-2) onboard the Advanced Land Observing Satellite-2 (ALOS-2), remote sensing data were used to map geologic structural and topographical features in the Kelantan river basin for identification of high potential risk and susceptible zones for landslides and flooding areas. A ScanSAR and two fine mode dual polarization level 3.1 images cover Kelantan state were processed for comprehensive analysis of major geological structures and detailed characterizations of lineaments, drainage patterns and lithology at both regional and district scales. Red-Green-Blue (RGB) colour-composite was applied to different polarization channels of PALSAR-2 data to extract variety of geological information. Directional convolution filters were applied to the data for identifying linear features in particular directions and edge enhancement in the spatial domain. Results derived from ScanSAR image indicate that lineament occurrence at regional scale was mainly linked to the N-S trending of the Bentong-Raub Suture Zone (BRSZ) in the west and Lebir Fault Zone in the east of the Kelantan state. Combination of different polarization channels produced image maps contain important information related to water bodies, wetlands and lithological units for the Kelantan state using fine mode observation data. The N-S, NE-SW and NNESSW lineament trends were identified in the study area using directional filtering. Dendritic, sub-dendritic and rectangular drainage patterns were detected in the Kelantan river basin. The analysis of field investigations data indicate that many of flooded areas were associated with high potential risk zones for hydro-geological hazards such as wetlands, urban areas, floodplain scroll, meander bend, dendritic and sub-dendritic drainage patterns, which are located in flat topograghy regions. Numerous landslide points were located in rectangular drainage system that associated with topographic slope of metamorphic and Quaternary rock units. Some large landslides were associated with N-S, NNE-SSW and NE-SW trending fault zones. Consequently, structural and topographical geology maps were produced for Kelantan river basin using PALSAR-2 data, which could be broadly applicable for landslide hazard mapping and identification of high potential risk zone for hydro-geological hazards.
\end{abstract}

\section{INTRODUCTION}

Structural field mapping is often difficult in heavily vegetated Terrain. This is the case with the study area where dense vegetation cover, deep weathering and scarcity of bedrock exposure hampers geological structure mapping over a long distance. In addition, the use of optical remote sensing data is limited due to the persistent cloud coverage of the study area for most part of the year (Pour and Hashim, 2014, 2015). The presence of linear tectonic structures is one of the important factors in geological hazard occurrences (Bannert, 2000a,b). Lineaments are represented by faults (linear features), lithological contacts between rock units and drainage patterns in any area (van der Pluijm and Marshak, 1997). Observation from satellite images (Landsat Thematic Mapper) in the Himalayan Mountains of Nepal and China revealed a clear connection between of active faults, associated with earthquakes and the occurrence of large landslides (Bannert, 2000a,b).

The Advanced Land Observing Satellite-2 (ALOS-2) was launched on May 24, 2014 as successor of ALOS-1 (launched on January 24, 2006 and decommissioned in May 2011). The ALOS-2 is exclusively installed with the Phased Array type Lband Synthetic Aperture Radar-2 (PALSAR-2) using microwaves to maximized its ability compare to the ALOS-1, on which three sensors (two optical and one microwave devices) were onboard (Suzuki et al., 2012). PALSAR-2 of the ALOS-2 has been significantly improved from the ALOS-1's PALSAR in all aspects, including resolution, observation band and time lag for data provision (Suzuki et al., 2012). ALOS-2 science capabilities include global environmental monitoring using the time-series PALSAR-2.

The research target also covers biospheric, cryospheric and coastal ocean research as well as disaster mitigation (Shimada, 2013). PALSAR-2 is a microwave sensor that emits L-band radio waves and receives their reflection from the ground to acquire information (Suzuki et al., 2012). It has three observation modes, including (i) Spotlight mode: the most detailed observation mode with 1 by 3 meters resolution and observation width of $25 \mathrm{~km}$; (ii) Strip map mode: a highresolution mode with the choice of 3 (ultra fine), 6 (high sensitivity) or 10 (fine) meters resolution and observation width of 50 or $70 \mathrm{~km}$; and (iii) ScanSAR mode: a broad area observation width of 350 (nominal) or 490 (wide) $\mathrm{km}$ and resolution of 100 or 60 meters (Yamamoto et al., 2013; Shimada et al., 2015). The wavelength of the L-band is relatively long among microwaves (C-band: about $6 \mathrm{~cm}$ and X- 
band: about $3 \mathrm{~cm}$ ), allowing it to travel all the way down to the ground through vegetation (Woodhouse, 2006, Pour and Hashim, 2014, 2015). Not only can information be, obtained about vegetation but information of the ground surface can be obtained as well. Additionally, L-band is not affected by the growth of vegetation, which is useful for SAR interference analysis (Interferometry). Therefore, L-band is capable to acquire changes on the land more precisely compared to other band's SAR when some diastrophism takes place due to an earthquake or a volcanic activity and floods or landslides caused by a natural disaster (Suzuki, 2014). The objective of this study is to map geologic structural and topographical features in the Kelantan river basin for identification of high potential risk and susceptible zones for landslides and flooding areas at regional and district scales.

\section{MATERIALS AND METHODS}

\subsection{Geology of the study area}

Peninsular Malaysia forms an integral part of the Southeast Asian continental core of Sundaland and comprises two tectonic blocks/terranes, the Sibumasu Terrane in the west and the Sukhothai Arc in the east, which were assembled by the Late Triassic (Pour and Hashim, 2015). The state of Kelantan is located in north-eastern corner of Peninsular Malaysia (Figure 1). The state of Kelantan is located in north-eastern corner of Peninsular Malaysia. Kelantan river is the major river in the region. It appears at the convergence of the Galas river and Lebir river near Kuala Kari and meanders over the coastal plain until it finally degrades into the South China Sea.

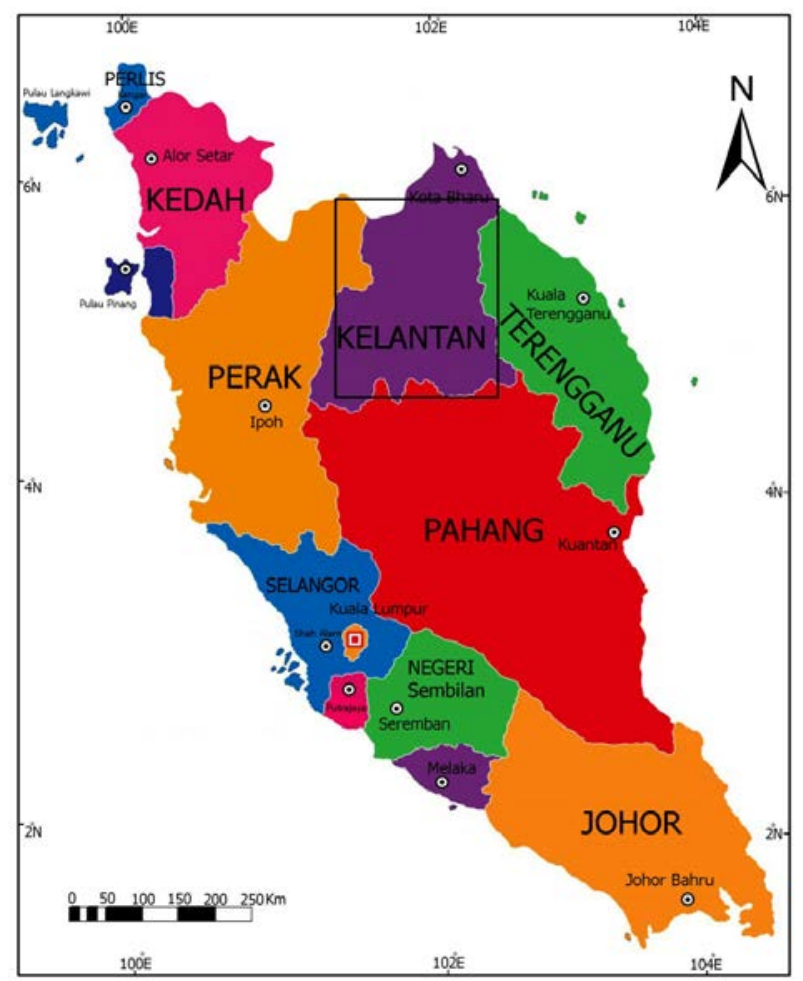

Figure 1. Location of the Kelantan state in Peninsular Malaysia.

Kelantan river basin covers $923 \mathrm{~km}^{2}$, which is about $85 \%$ of the Kelantan state's surface area. It is composed of flat slope to moderately sloping areas in northern part and steep scraps and high slopes in the southern part of the river basin. A wide variety of rocks consisting of igneous, sedimentary and metamorphic rocks are distributed in a north-south trend in the Kelantan state.

Typically, four types of rocks are classified in the region, including granitic rocks, sedimentary/metasedimentary rocks, extrusive rocks (volcanic rocks) and unconsolidated sediments (Figure 2). Localised geological features comprise faulting and jointing in the granitic rocks and folding, faulting and jointing in the sedimentary rocks. Granitic rocks are distributed in the west (the Main Range granite) and east borders (the Boundary Range granite) of the state of Kelantan (Department of Minerals and Geoscience Malaysia, 2003).

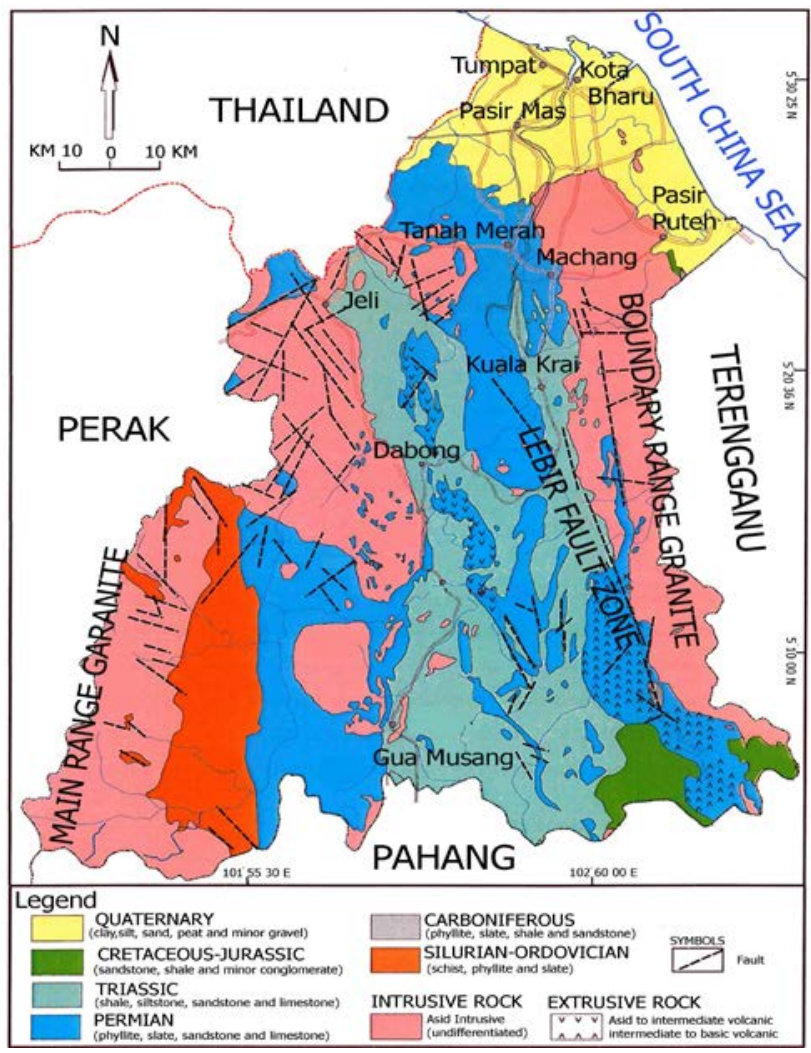

Figure 1. Geologic map of the Kelantan state.

\subsection{Remote sensing data}

In this investigation, a ScanSAR mode dual polarization (level 3.1) and two Fine mode dual polarization (level 3.1) PALSAR2 scenes were obtained from ALOS-2 data distribution consortium online system Remote Sensing Technology Center of Japan (RESTEC) (http://www.restec.or.jp) and PASCO Corporation (http://en.alos-pasco.com; https://satpf.jp/) for comprehensive analysis of major geological structures and detailed characterizations of lineaments in the state of Kelantan. The data used in this study were acquired during dry season (June to August, 2015). The data were processed using the ENVI (Environment for Visualizing Images) version 5.2 software package.

\subsection{Data analysis}

Systematic image processing techniques were implemented to the PALSAR-2 data for geological structures and lineament 
mapping at both regional and district scales in the state of Kelantan. In this study, the median spatial convolution filter was used for noise removal and smoothing the PALSAR-2 images. The median filter is a particularly useful statistical filter in the spatial domain, which effectively remove speckle (salt and pepper noise) in radar images without eliminating fine details (Schowengerdt, 2007).

The directional nature of geological lineaments accentuates the need for directional filtering to obtain maximum structural mapping efficacy. Edge enhancing filter highlights any changes of gradient within the image features such as structural lines. A linear filter is calculated in the spatial domain as a weighted sum of pixels within the moving window. This discrete convolution between the input image $f$ and the window response function $w$, both of size $N_{X} * N_{Y}$, is written mathematically for the output pixel gij,

$$
g i j=\sum_{m=0}^{N_{x}-1} \sum_{n=0}^{N_{y}-1} f_{m n} w_{i-m j-n}
$$

and expressed symbolically in the convenient form,

$$
g=f^{*} w \text {. }
$$

Since the nonzero extent of the window is typically much smaller than the image, the sum in Eq.(1) does not have to be over every pixel. If the window is $w_{x} * w_{y}$ pixels, we can write an alternate expression,

$$
g i j=\sum_{m=i-W_{y} / 2}^{i+W_{y} / 2} \sum_{n=j-W_{x} / 2}^{j+W_{x} / 2} f_{m n} w_{i-m j-n}
$$

Where $w$ is centred at $(0,0)$ and is nonzero over $\pm w_{x / 2}$ and \pm $w_{x / 2}^{2}$. In this form, we can clearly see that the output pixel is a weighted sum of pixels within a neighbourhood of the input pixel. The distinguishing characteristic of a linear filter is the principle of superposition, which states that the output of the filter for a sum of two or more inputs is equal to the sum of the individual outputs that would be produced by each input separately. This is achieved with a convolution because Eq. (2) is a linear weighted sum of the input pixels. Furthermore, the filter is shift-invariant if the weights do not change as the window moves across the image (Schowengerdt, 2007).

Directional filters were used to enhance specific linear trends in the median resultant image. Four principal directional filters: NS, E-W, NE-SW, and NW-SE with $5 * 5$ and $7 * 7$ kernel sizes were applied to ScanSAR and Fine scenes, respectively. 5*5 kernel matrix was selected for ScanSAR scene to enhance rough/smooth and semi-rough features at regional scale in northern part of Peninsular Malaysia. $7 * 7$ kernel matrix was applied to Fine scenes for enhancing semi-smooth and smooth/rough features at district scale in the Kelantan state (Jensen, 2005). Directional filter angles were adjusted as N-S: $0^{\circ}$, E-W: $90^{\circ}$, NE-SW: $45^{\circ}$, and NW-SE: $135^{\circ}$. North (up) is zero degrees and the other angles are measured in the counterclockwise direction. Image Add Back value was entered $60 \%$.

\section{RESULTS AND DISCUSSION}

A wide-swath ScanSAR observation mode of PALSAR-2 was used for comprehensive analysis of major geological structures, which shows mega-geomorphology and mega-lineaments in the Kelantan state. Figure 3 shows RGB colour-composite of $\mathrm{HH}$ polarization channel in red, HV polarization channel in green and $\mathrm{HH}+\mathrm{HV}$ polarization channel in blue for the ScanSAR median resultant image. The RGB colour-composite yields an image with great structural details and geomorphological information. The different colors in the image indicate different backscattering signals from the ground.

The Main Range granites located in in the western part of the image and the Boundary Range granite in the east borders of Kelantan state appear as light green to green in colour, which shows the regions with high altitude in the scene (Fig. 3). Major transcrustal lineaments such the Bentong-Raub Suture Zone (BRSZ) and Lebir Fault Zone are also detected. Quarternary deposits, Triassic marine siliciclastics, volcaniclastics, sandstone and limestone are manifested as pink to purple tones consisting of lands with low elevation (Fig. 3). Lakes and main river systems are portrayed blue to dark blue in the image. In fact, the lines formed by blue to dark blue colour on the image are faults and fracture zones occupied by streams.

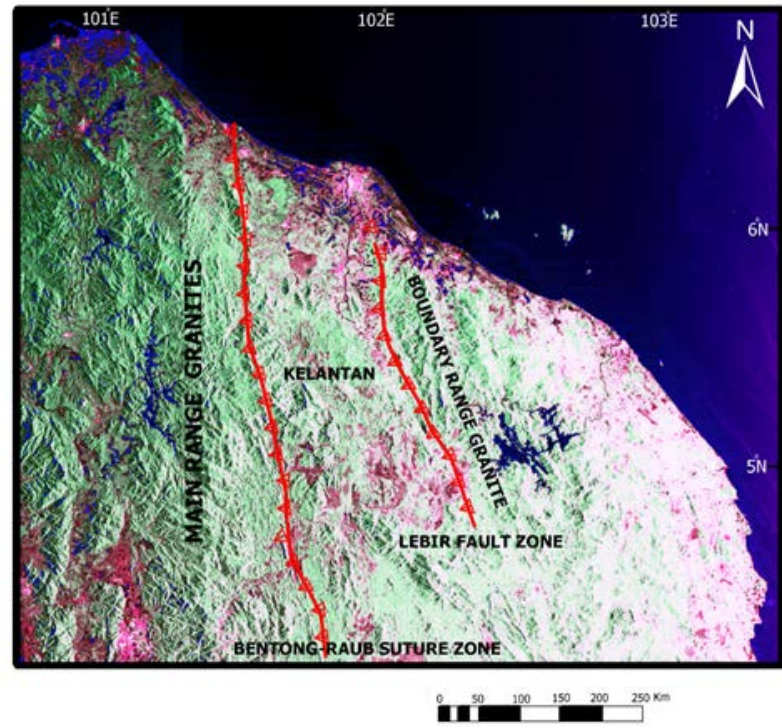

Figure 3. RGB colour combination (HH, $\mathrm{HV}$ and $\mathrm{HH}+\mathrm{HV}$ polarization channels) of PALSAR-2 Scan SAR scene covering northern part of the Peninsular Malaysia.

Figure 4 shows the resultant image map for N-S, NE-SW, and NW-SE (R: $0^{\circ}, \mathrm{G}: 45^{\circ}$, B: $135^{\circ}$ ) directional filters. Major change in deformation style is obvious from the west to the east in Figure 5. Structural analysis reveals four distinct parts from the west to the east, including (i) western part of the scene by ductile fabrics; (ii) western of the BRSZ affected mainly by brittle deformation; (iii) ductile-brittle deformation between the BRSZ and Lebir Fault Zone; and (iv) brittle-ductile fabrics between Lebir Fault Zone and eastern coastal line.

Lineament occurrence in Figure 5 is mainly linked to the N-S trending of the BRSZ and Lebir Fault Zone. Generally, major faults are strike-slip with both dextral and sinistral movements, which trend N-S and NW-SE. NW-SE trending strike-slip faults moved sinistrally in the Lebir Fault Zone. The sinistral 
The International Archives of the Photogrammetry, Remote Sensing and Spatial Information Sciences, Volume XLII-4/W1, 2016 International Conference on Geomatic and Geospatial Technology (GGT) 2016, 3-5 October 2016, Kuala Lumpur, Malaysia

movement along the Lebir Fault Zone is responsible to the formation of folding and reverse faulting adjacent to the fault and surrounding area. These structures characterized transpressive tectonic regime in the Peninsular Malaysia (Richter et al., 1999; Harun, 2002).

The collision zone and compressional structures appear clearly in the west of the BRSZ in Main Range granites (Figure 5). Deformation in this region shows the shortening zone oriented parallel to the BRSZ. Several faults, joints and fractures represent brittle deformation events in the region that mostly strike NW-SE. Generally, most of the short lineaments are clustered in the collision zone. Ductile deformation in the western margin of the image (Figure 4) includes upright asymmetrical mega folds with axial surfaces oriented W-E. Hence, the contractional strain direction affected this domain is from NE-SW followed by dextral shearing. The deformed area zone between the BRSZ and Lebir Fault Zone represents faults system and folded area.

NW-SE striking strike-slip faults and NE-SW normal faults are dominated brittle structural elements within this domain. Ductile deformation is demonstrated by several open upright folds, which have W-E to NE-SW axial plans (Fig. 4). Brittleductile fabrics in the eastern part of image between Lebir Fault Zone and eastern coastal line illustrate curved shear zone that occupied by several N-S and NW-SE striking faults, fractures and joints. A mega concentric fold surrounds the shear zone with a WE striking axial surface. According to the orientation of the lineaments, sinistral movement along the Lebir Fault Zone is generated the tectonic features. Some N-S and NE-SW trending normal faults and small curvatures are also identifiable near the eastern coastal line (Figure 4).

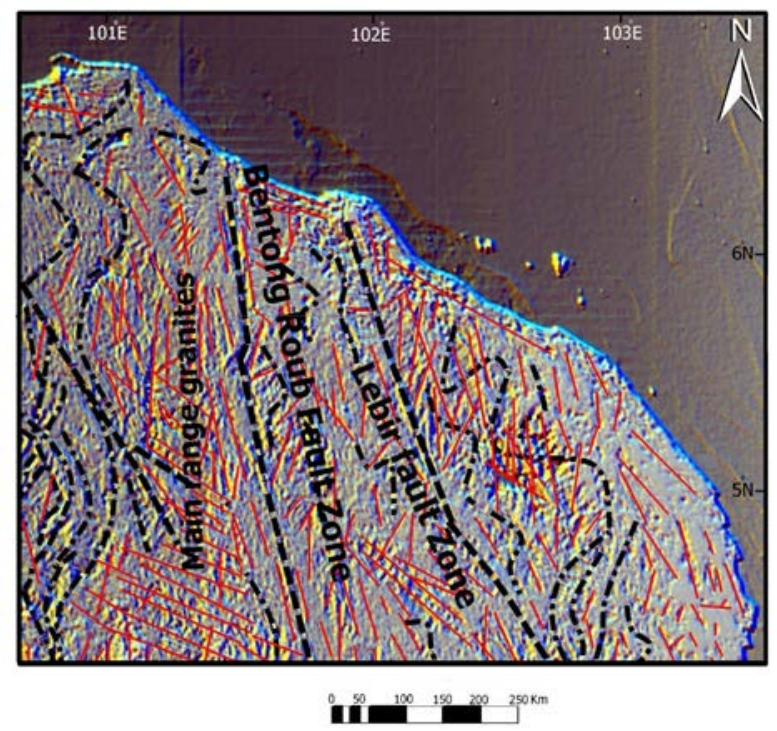

Figure 5. ScanSAR image map derived from N-S $\left(0^{\circ}\right)$, NE-SW $\left(45^{\circ}\right)$, and NW-SE $\left(135^{\circ}\right)$ directional filters for northern part of the Peninsular Malaysia. Explanation for the figure: dashed black lines = major faults; dot-dashed lines $=$ folds and curvilinear; red lines $=$ faults and fractures .

Figure 5 shows fine mode merged image of the northern and southern parts of the Kelantan state. In this figure, $\mathrm{HH}$ polarization channel was assigned to red colour, HV polarization channel to green colour and $\mathrm{HH}+\mathrm{HV}$ polarization channels to blue colour for generating an RGB image for the study area. This colour combination produced an image map contains important information related to water bodies, wetlands and geological structural features. River systems and lakes appear black especially in north-eastern part of the image and wetlands as mauve colour (Figure 5). Wetlands are more distributed in northern part of the study area (Figure 5). A vast wetland (strong mauve colour) represents clearly in the central north segment of the image. Several wetlands as light to strong mauve colour are observable in central east, south and southwestern part of the image (Figure 5).

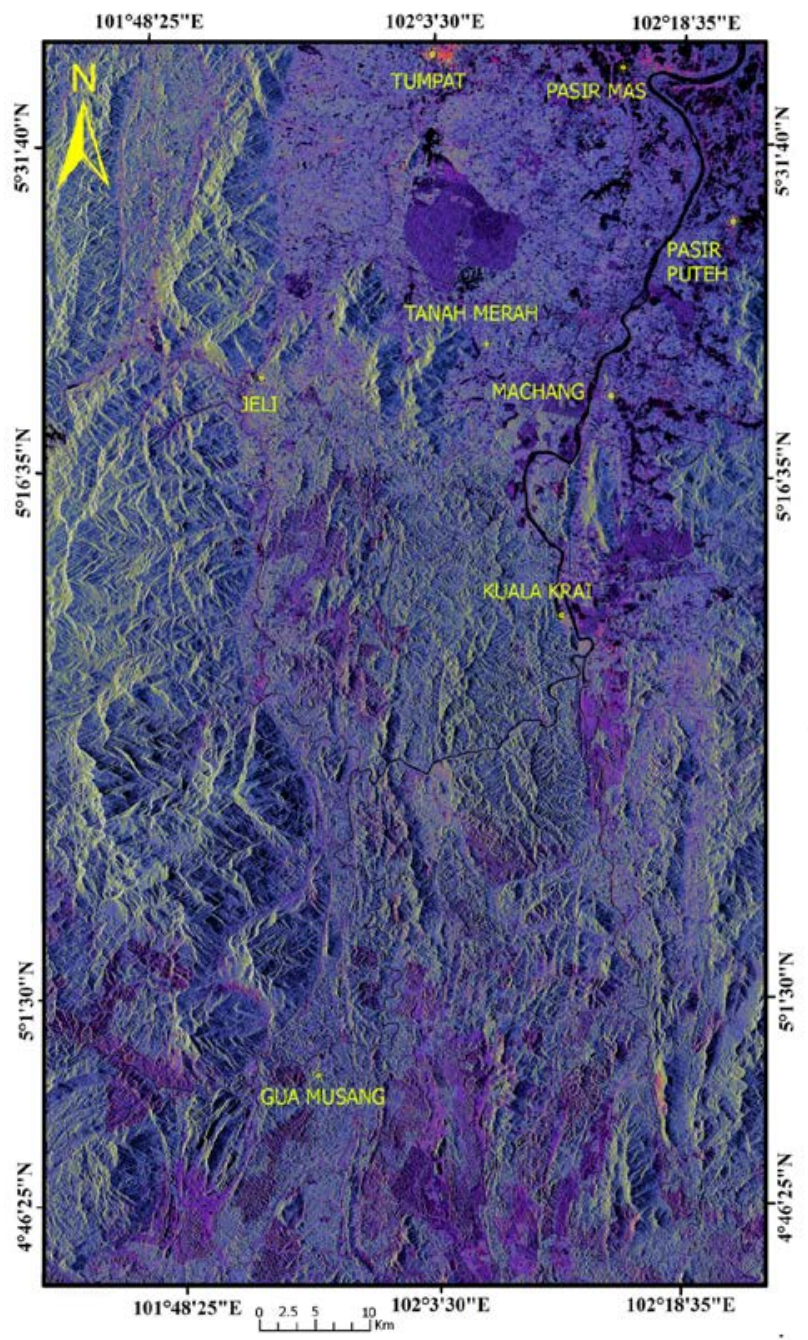

Figure 6. RGB colour-composite image of $\mathrm{HH}, \mathrm{HV}$ and $\mathrm{HH}+\mathrm{HV}$ polarization channels derived from fine mode merged image of the northern and southern parts of the Kelantan state.

Four directionally filtered images of fine mode observation, which contain enhanced information for set of lineaments in $\mathrm{N}$ S, E-W, NE-SW and NW-SE direction, were used for lineament mapping in the Kelantan state. Figure 7 shows structural map for the Kelantan state, which is derived from the resultant image of directional filtering to HV polarization channel. It should be noted that the locations of wet lands and drainage patterns are also portrayed in this figure. The most important structural features in the image map are fault zones, river systems and drainage lines patterns (Figure 8). Within the study area two large fault zones are presented, which are the BRSZ in the north-west and Lebir Fault Zone in the south-east. The N-S, 
NE-SW and NNE-SSW lineament trends are commonly dominant in the image map. The dominant lineaments tend to run in the N-S direction, which is mainly linked to the N-S trending of the BRSZ (in the west) and Lebir Fault Zone (in the east). Additionally, few short NW-SE trending lineaments are detected in the western and eastern parts of the study area (Fig. 7). The N-S and NE-SW striking system distributed in the south eastern segment of the region is particularly related to Lebir Fault Zone. Pattern of the lineament map in north-western part of the image map displays the occurrence of BRSZ fault zone, which contains lineaments in N-S and NNE-SSW directions. Most of the short and smaller faults follow the N-S, NE-SW and NNE-SSW trends as the major fault systems in the Kelantan state. It seems that the NW-SE faults are the youngest faults in the study area due to low frequency of lineaments in this trend.

The drainage system in the Kelantan river basin shows dendritic, sub-dendritic and rectangular patterns (Fig. 7). It is evident that the drainage pattern is apparently being controlled by structure and lithology in the study area. Structural and topographical feature map of the Kelantan river basin is shown in Figure 8. It is evident that most of the dendritic and subdendritic drainage patterns are located in low lands and the rectangular drainage pattern is dominated in high lands in the Kelantan river basin.

Field observations were conducted between 20 and 25 June 2015 to compare the detected high potential risk and susceptible zones with high damaged areas in recent flooding events in the Kelantan river basin. GPS surveying was carried out in Tanah Merah, Machang, Jeli, Kuala Krai and Gua Musang districts in the Kelantan river basin. 453 landslide affected zones and flooded areas locations were recorded in forest, rubber, bushes (degraded forest), mixed crops, oil palm, cleared land, urban area and agriculture lands. Rock samples were taken from the lithological units of landslide affected sites.

Ground photographs were taken of the high damaged areas after 2015 flooding event. Numerous landslides affected points were recorded in high-altitude segment of south and south-western part of the Kelantan state. As mentioned above, high drainage density of rectangular system is governed in this domain. The drainage density affects runoff, in that a high drainage density drains runoff water rapidly, decreases the lag-time and increases the peak of hydrograph. Consequently, the slope of the land in the south and south-western regions increases the speed and extent of water and sediment transportation to the Kelantan river basin during heavy monsoon rainfall. Most of the landslide affected points were located in topographic slope of metamorphic and Quaternary rock units.

However, some landslides occurred in fracture zones of weathered igneous rock units. Some large landslide affected zones were recorded in the intersection of longitude and latitude between ( $5^{\circ} 08^{\prime} 02^{\prime \prime}$, E $\left.101^{\circ} 58^{\prime} 53^{\prime \prime}\right)$, ( $\mathrm{N}^{\circ} 08^{\prime} 14^{\prime \prime}$, E $101^{\circ} 59^{\prime}$ $\left.06^{\prime \prime}\right)$, (N $5^{\circ} 08^{\prime} 24^{\prime \prime}$, E $\left.101^{\circ} 59^{\prime} 21^{\prime \prime}\right)$ and (N $5^{\circ} 09^{\prime} 03^{\prime \prime}$, E $101^{\circ} 59^{\prime}$ $\left.41^{\prime \prime}\right)$. These landslide points were associated with N-S, NNESSW and NE-SW trending fault zones.

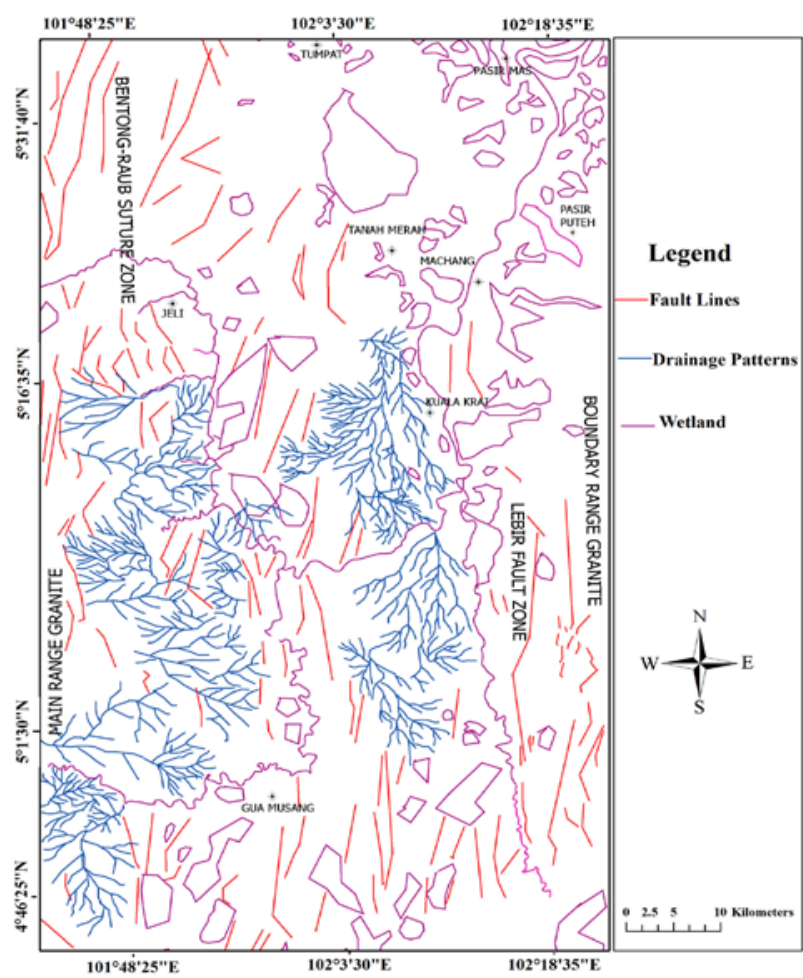

Figure 7. Structural lineament map of the Kelantan state derived from directional filtering to $\mathrm{HV}$ polarization channel.

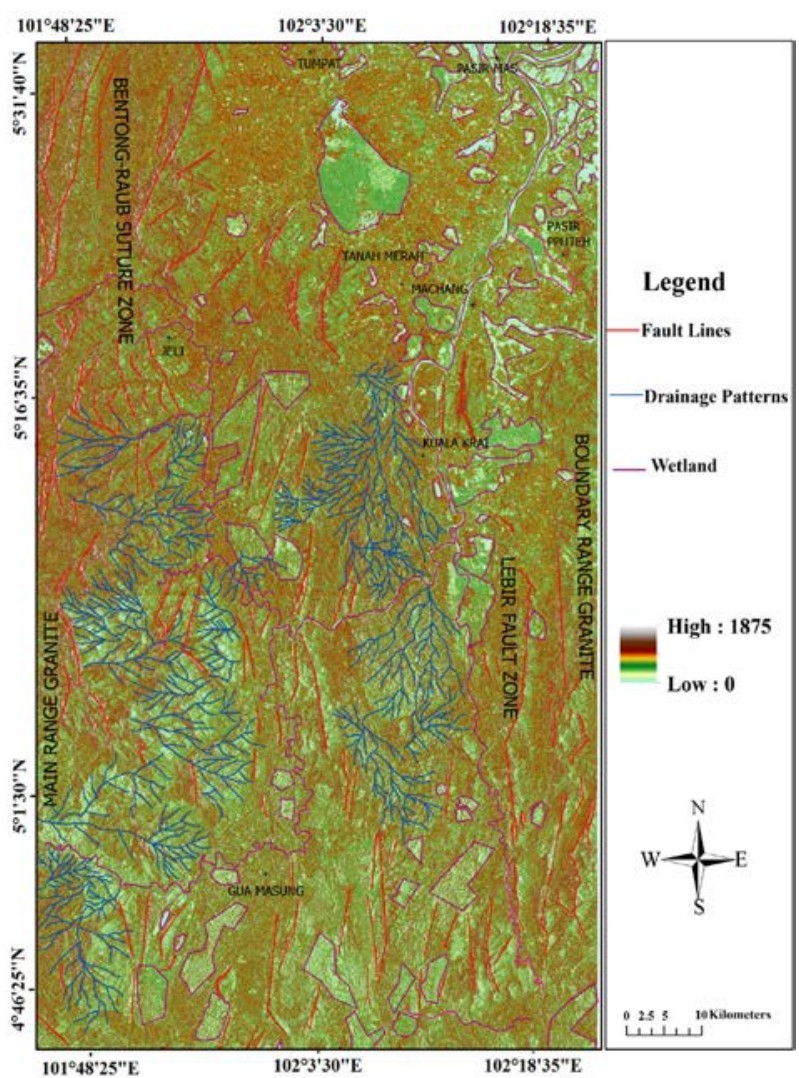

Figure 8. Structural and topographical feature map of the Kelantan river basin. 


\section{CONCLUSIONS}

Results of this investigation indicate that the PALSAR-2 onboard the ALOS-2 has proven to be successful advanced remote sensing satellite data for disasters monitoring in tropical environments. Analysis of the PALSAR-2 data provided significant information for identifying high potential risk and susceptible zones for natural hazards of geological origin in the Kelantan river basin, Malaysia. Wetlands, floodplain scroll, meander bend, dendritic and sub-dendritic drainage patterns and urban areas were identified as high potential risk zones for hydro-geological hazards.

Landslide recurrence regions were detected in high-altitude segment of south and south-western part of the Kelantan state, which is dominated with high density of rectangular drainage pattern and topographic slope of metamorphic and quaternary rock units. Some of the large landslide zones were associated with N-S, NNE-SSW and NE-SW trending fault systems. Structural and topographical geology maps were produced for the Kelantan river basin that could be used to facilitate the planning of geo-hazards mitigation. In conclusion, the results of this investigation has great potential assistance in terms of total solution to flood disaster management in the Kelantan river basin by providing important source of information to assess the potential for many natural hazards of geological origin.

\section{ACKNOWLEDGEMENTS}

This study was conducted as a part of Tier 1 (vote no: Q.J130000.2527.13H13), research university grant category. We are thankful to the Universiti Teknologi Malaysia for providing the facilities for this investigation.

\section{REFERENCES}

Department of Minerals and Geoscience Malaysia (2003). Quarry Resource Planning for the State of Kelantan. Osborne and Chappel Sdn. Bhd.

Jensen, J.R. (2005). Introductory Digital Image Processing: A remote sensing perspective. Pearson Prentice Hall, Upper Saddle River NJ 07458. Third edition, p: 276-287.

Pour, A.B., Hashim, M., 2015 Structural mapping using PALSAR data in the Central Gold Belt Peninsular Malaysia, Ore Geology Reviews, vol.64, pp. 13-22.

Pour, A.B., Hashim, M., 2014. Structural geology mapping using PALSAR data in the Bau gold mining district, Sarawak, Malaysia, Adv. Space Research, vol.54 (4), pp. 644-654,

Schowengert, R.A.m, 2007. Remote sensing: models and methods for image processing," 3rd ed, Burlington, M.A, Academic Press, Elsevier. pp. 229-243.

Shimada, M. (2013). ALOS-2 science program. Proceedings of IGARSS (IEEE international Geoscience and Remote Sensing symposium), Melbourne, Australia, July 21-26, 2013.

Shimada, M., Watanabe, M., Motooka, T., Kankaku, Y., Suzuki, S. (2015). Calibration and validation of the PALSAR-2.
Proceedings of the IGARSS (International Geoscience and Remote Sensing Symposium) 2015, Milan, Italy, July 26-31, 2015.

Suzuki, S., Kankaku Y., Imai, H., Osawa Y. (2012). "Overview of ALOS-2 and ALOS-3", Proceedings of SPIE,' Earth Observing Missions and Sensors: Development, Implementation, and Characterization II,' Vol. 8528, Kyoto, Japan, October 29, 2012, 852811 (November 9, 2012); doi:10.1117/12.979184

Suzuki, S. (2014). "Advanced Land Observing Satellite-2 "DAICHI-2" (ALOS-2) - Mission talk by team leaders," JAXA, May 2014,

URL: http://global.jaxa.jp/projects/sat/alos2/leaders.html

Woodhouse, I.H. (2006). Introduction to microwave remote sensing. CRC Press, Taylor \& Francis Group, Boca Raton.

Yamamoto, T., Kawano, I., Iwata, T., Arikawa, Y., Itoh, H., Yamamoto, M., Nakajima, K. (2013). Autonomous Precision Orbit Control of ALOS-2 for Repeat-Pass SAR Interferometry. Proceedings of IGARSS (IEEE International Geoscience and Remote Sensing Symposium), Melbourne, Australia, July 2126, 2013. 